\title{
Electrochemical monitoring of methyl parathion degradation based on carbon fiber microelectrodes (CFME)
}

\author{
Issa TAPSOBA* and Boukaré KABORE \\ Laboratoire de Chimie Organique: Structure et Réactivité, Département de Chimie, Université de \\ Ouagadougou, 03 BP 7021 Ouagadougou 03, Burkina Faso; Phone : + 226706255 36; \\ Fax : + 22650307242 \\ *Corresponding author, E-mail: issa.tapsoba@univ-ouaga.bf
}

\begin{abstract}
The electrochemical degradation of methyl parathion (MP) has been investigated by using carbon fiber microelectrodes (CFME) as working electrode and acetate buffer $\mathrm{pH} 5.2$ as supporting electrolyte. $p$ nitrophenol (PNP) and $p$-aminophenol (PAP) recognized as by-products of MP degradation process have been detected and identified in real time using square wave voltammetry. This study shows for the first time that CFME could be used to follow MP degradation in real time and to identify its stables metabolites.

(C) 2012 International Formulae Group. All rights reserved.
\end{abstract}

Keywords: Organopollutants, decomposition, p-nitrophenol, p-aminophenol, Cyclic voltammetry, Square wave voltammetry.

\section{INTRODUCTION}

Organophosphates (OP) compounds are amongst the most consumed pesticides used to improve yields in agriculture production (Castanho et al., 2003). Belonging to this family, methyl parathion (MP) is a very efficient insecticide against many pests in important cultures such as cotton, sugar cane, cereals, and vegetables. It is a well-known inhibitor of acetylcholinesterase, and therefore classified in toxicological class 1 (Jaffrezic 2003).

In the environment, the degradation of MP leads to various by-products including stable compounds as $p$-nitrophenol (PNP) and $p$-aminophenol (PAP) (Moctezuma et al., 2007; Liu et al., 2006). The development of analytical methods for the determination of environmental pollutants, mostly at trace level, is a great challenge (Trojanowicz 2002). In the literature, cathodic electrochemical detection has been widely used for the determination of many electroactive compounds (Castanho et al., 2003; Liu 2006). So, for simultaneous detection of MP and PNP in a mixture, we previously proposed the use of novel modified carbon fiber microelectrode (CFME) by tetrasulfonated nickel phtalocyanine (Tapsoba et al., 2009). The main aim of this study is to show that carbon fiber microelectrode could be used to follow in real time the decomposition of some organophosphorus pollutants and to identify their stable electroactive metabolites. Herein, we report, at laboratory scale, a direct electrochemical monitoring of methyl 
parathion degradation in real time by square wave voltammetry (SWV) using carbon fiber microelectrodes as working electrode. The nature of the by-products formed during the degradation of MP has been identified and discussed using cyclic voltammetry response.

\section{MATERIALS AND METHODS Reagents}

Standards of methyl parathion MP (99.8\%), $p$-aminophenol PAP (98\%) were purchased from Sigma-Aldrich. $p$-nitrophenol PNP (99\%) was purchased from Fluka. Acetic acid $(99.8 \%)$, acetonitrile $(99.9 \%)$, sodium chloride $(99.5 \%)$ and sodium acetate were purchased from Prolabo.

\section{Apparatus}

Cyclic voltammetry (CV) and square wave voltammetry (SWV) measurements were performed using an electrochemical analyzer PalmSens (PalmSens Instrument, Netherlands) connected to a personal computer using Ivium PC and PSLite softwares. A three-electrode configuration was employed consisting of a carbon fiber microelectrode $(12 \mu \mathrm{m}$ diameter purchased from WPI, USA). The carbon electrode surface was renewed by a homemade electrochemical treatment. Indeed, the carbon fiber microelectrodes were first pretreated electrochemically in a mixture of sulphuric $\begin{array}{lllll}\text { acid } & \mathrm{H}_{2} \mathrm{SO}_{4} & (0.5 \mathrm{M}) / \text { Ethanol } & (50 / 50 & \mathrm{w} / \mathrm{w})\end{array}$ followed by a treatment in $0.2 \mathrm{M}$ acetate buffer (pH 5.2) using following conditions: potential scanning rate: $100 \mathrm{mVs}^{-1}$ in the potential range -1.0 to $1.5 \mathrm{~V} / \mathrm{Ag} / \mathrm{AgCl}(\mathrm{KCl}$ 0.1 mol. $\mathrm{L}^{-1}$ ) during 20 cycles. The quality of these microelectrodes was controlled after carrying out of the electrochemical response of the probe $\mathrm{Fe}(\mathrm{CN})_{6}{ }^{4-}$. $\mathrm{An} \mathrm{Ag} / \mathrm{AgCl}(\mathrm{KCl} 0.1$ mol $\mathrm{L}^{-1}$ ) electrode was used as reference and stainless wire as auxiliary electrode. A quality control of the CFME cleanness with visual and electrochemical tests was used. Electrochemical experiments were carried out in a $10-\mathrm{mL}$ glass voltammetric cell at room temperature.

\section{Analysis}

Stock solution of methylparathion (1 g. $\mathrm{L}^{-1}$ ) was prepared by dissolving the equivalent mass of MP in acetonitrile. $0.2 \mathrm{M}$ of acetate buffer ( $\mathrm{pH}$ 5.2) was used as the supporting electrolyte.

We carried out the monitoring of the kinetical degradation of $200 \mathrm{mg} / \mathrm{L}$ of $\mathrm{MP}$ in acetate buffer (pH 5.2) using CFME by square wave voltammetry. These square wave voltammetry parameters are previously optimized by Sbai et al. (2007) for a high current response of MP. Square-wave voltammetry (SWV) scanning was performed from -1.3 to $+1 \mathrm{~V}$ versus $\mathrm{Ag} / \mathrm{AgCl}(\mathrm{KCl} 0.1$ mol L $\mathrm{L}^{-1}$ ) with a step potential of $10 \mathrm{mV}$, amplitude of $60 \mathrm{mV}$, and a frequency of 60 $\mathrm{Hz}$. Indeed, we carried out a voltammogram of MP $\left(200 \mathrm{mg} \mathrm{L}^{-1}\right)$ at the initial time $(\mathrm{t}=0)$ and after that this solution was kept at room temperature for further investigation. Voltammograms have been recorded at 19, 30 and 45 hours after the initial time following MP degradation.

\section{RESULTS AND DISCUSSION}

Electrochemical behavior of MP, PNP and pap at carbon fiber microelectrode (CFME)

Cyclic voltammograms using CFME as working electrode were investigated to examine the electrochemical behaviour of MP, PNP and pap. Figure 1 shows an example of the response of MP and as it is previously described (Tapsoba et al., 2009; Sbaï et al., 2007), one can distinguish three well defined peaks illustrating the reduction of MP at -0.95 $\mathrm{V},-0.35 \mathrm{~V}$ and $0.10 \mathrm{~V}$ respectively.

As described elsewhere in the literature (Tapsoba et al., 2009; Sbaï et al., 2007), the first irreversible (peak I) at $-0.95 \mathrm{~V}$ corresponds to the reduction of nitro group of MP to a hydroxylamine as illustrated on Schema 1 after 4 electrons transfer. During the reverse potential scan, one can observe a reversible peak (II and III) at $-0.30 \mathrm{~V}$ and 0.10 $\mathrm{V}$ respectively attributed to a two electrons transfer on the hydroxylamine formed according to Schema 2. 
In the case of PNP, the same behaviour is observed on the voltammogram (curve not shown) and this fact is due to the similarity of their structure. Indeed, due to the presence of nitro group in PNP structure, one can note the presence of reduction peak of nitro group at comparable potential after 4 electrons consumed followed by a reversible peak corresponding of 2 electron transfer on hydroxylamine derivative generated. These profiles are consisting with those described in the literature (De Souza and Machado, 2006; Tan X. et al., 2010) for OPs and nitroaromatic compounds. In Table 1, we summarized the different characteristics of these two nitroaromatic compounds.

One can note in Table 1 that the nitro group of PNP presents more cathodic potential than MP. This observation can be explained by the mesomeric effect of hydroxyl group $\mathrm{OH}$ of PNP which leads to increase the electronic charge toward the nitro group and subsequently makes it less reducible comparatively to MP. Moreover, it appears that the oxidation peak of $\mathrm{NHOH}$ is different in the two cases and this result is in agreement with previous reported data using square wave voltammetry investigation (Tapsoba et al., 2009).

In addition, in the case of PNP and when the reverse anodic potential reaches the value of $+1 \mathrm{~V}$, one can observe the presence of an oxidation peak corresponding to the oxidation of the hydroxyl group. This result is in agreement with a previous work (Pontie et al., 2011) for which the authors noted a fooling of the microelectrode when the scanning reaches this range potential. In order to avoid this pollution, we voluntary poised the reverse anodic potential at $+0.8 \mathrm{~V}$ versus $\mathrm{Ag} / \mathrm{AgCl}\left(\mathrm{KCl} 0.1 \mathrm{~mol} \mathrm{~L}^{-1}\right)$.

Furthermore, a deep examination of the signal of Figure 1 shows that the intensity of peak I corresponding to nitro group reduction is higher than 4 electrons transfer as reported and comparatively to the intensity of peak II and III which correspond to a transfer of 2 electrons. This difference between current intensity could be explained by the contribution of reduction current of dissolved oxygen of the buffer which has not been degassed in order to have the real conditions of MP degradation in environment. When the same investigation is carried out under nitrogen atmosphere (Tapsoba et al., 2009), one can observe the ratio between the reduction current of the nitro group and the hydroxylamine group equal to 2 .

When the cyclic voltammetry is carried out on the PAP, only one anodic peak is observed (Figure not shown). This irreversible peak located at $+0.30 \mathrm{~V}$ versus $\mathrm{Ag} / \mathrm{AgCl}$ $\left(\mathrm{KCl} 0.1 \mathrm{~mol} \mathrm{~L}^{-1}\right)$ is attributed to the oxidation of amino group of PAP after one electron consumption. This result is in agreement with previous reported work on the anodic oxidation of amine derivatives (Haouas et al., 2004; Cui et al., 2002).

\section{Monitoring of the degradation of MP by square wave voltammetry using cfme}

Figure 2 illustrates the voltammograms obtained respectively at time $t=0,19,30$ and 45 hours following the MP degradation by square wave voltammetry.

The voltammogram recorded at initial time $(\mathrm{t}=0)$ exhibits two peaks (peak I at -0.95 $\mathrm{V}$ and peak II at $-0.1 \mathrm{~V}$ versus $\mathrm{Ag} / \mathrm{AgCl}(\mathrm{KCl}$ $\left.0.1 \mathrm{~mol} \mathrm{~L}^{-1}\right)$ ) corresponding respectively to the reduction of nitro group and the hydroxylamine issued from nitro reduction as reported in the literature (Tapsoba et al., 2009).

When the recording was carried out after 19 hours following MP degradation, the peak I decrease, indicating that MP concentration lowered over this time. At this time, a new peak III appears at $+0.45 \mathrm{~V}$ versus $\mathrm{Ag} / \mathrm{AgCl}\left(\mathrm{KCl} 0.1 \mathrm{~mol} \mathrm{~L}^{-1}\right)$. This peak, which was absent at the initial time, could be attributed to the oxidation of a new component formed following the partial degradation of MP.

At $\mathrm{t}=30$ and 45 hours, the peak I decreases more and its potential shifts towards cathodic values to reach a value which is close to that obtained for nitro group of PNP. These observations suggest that PNP was formed 
following the decomposition of MP over time (Moctezuma et al., 2007). The formation of PNP during the degradation process is also confirmed one the one hand by the oxidation peak II which becomes large proving a recovery of different signal issued from the oxidation of hydroxylamine derivatives of remaining MP and PNP formed. There, results are in agreement with those reported previously by Cui et al. (2002).

Following the report of Pritchard et al., (1987), the general degradation process of MP is described by the below schema (Schema 3).

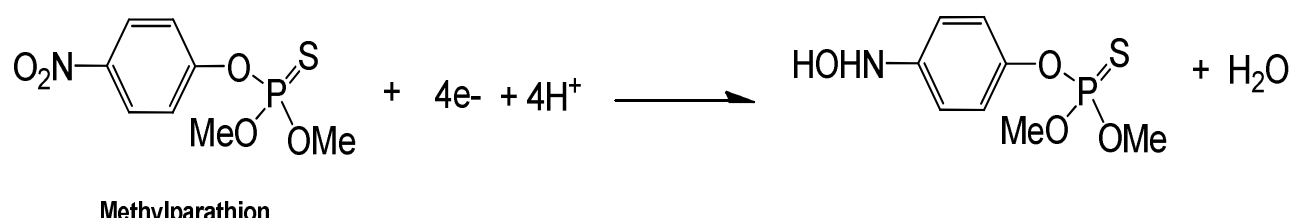

Schema 1: Equation illustrating the electrochemical reduction of nitro group of MP to hydroxylamine.

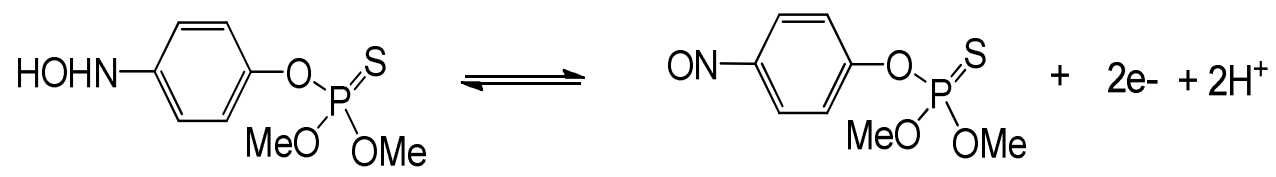

Schema 2: Equation illustrating to the electrochemical oxidation of hydroxylamine to nitroso.

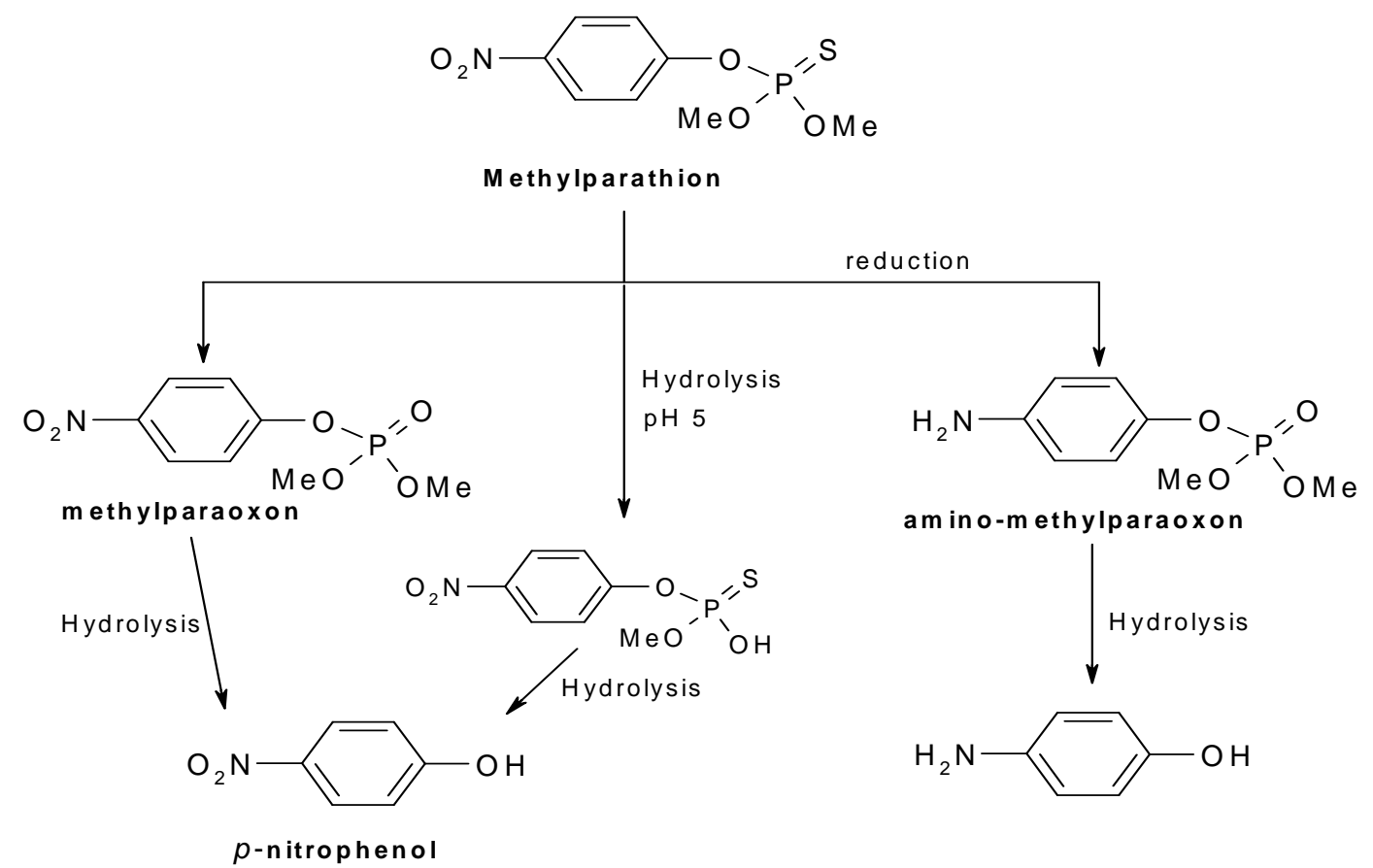

Schema 3: Mechanism of decomposition of parathion methyl. 


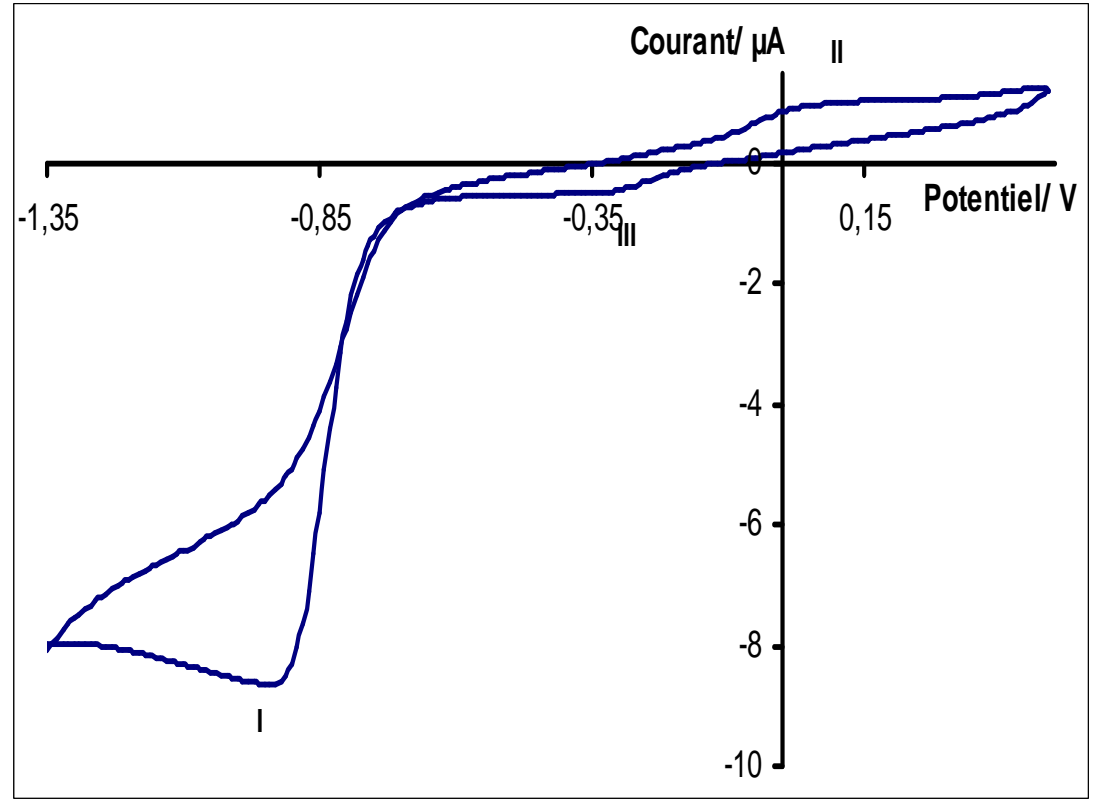

Figure 1: Cyclic voltamogramm of MP $\left(200 \mathrm{mg} \cdot \mathrm{L}^{-1}\right)$ performed at CFME in acetate buffer $\mathrm{pH} 5.2$. Reference $\mathrm{Ag} / \mathrm{AgCl}\left(\mathrm{KCl} 0.1 \mathrm{~mol} \mathrm{~L}^{-1}\right)$. Scan rate $=100 \mathrm{mVs}^{-1}$.

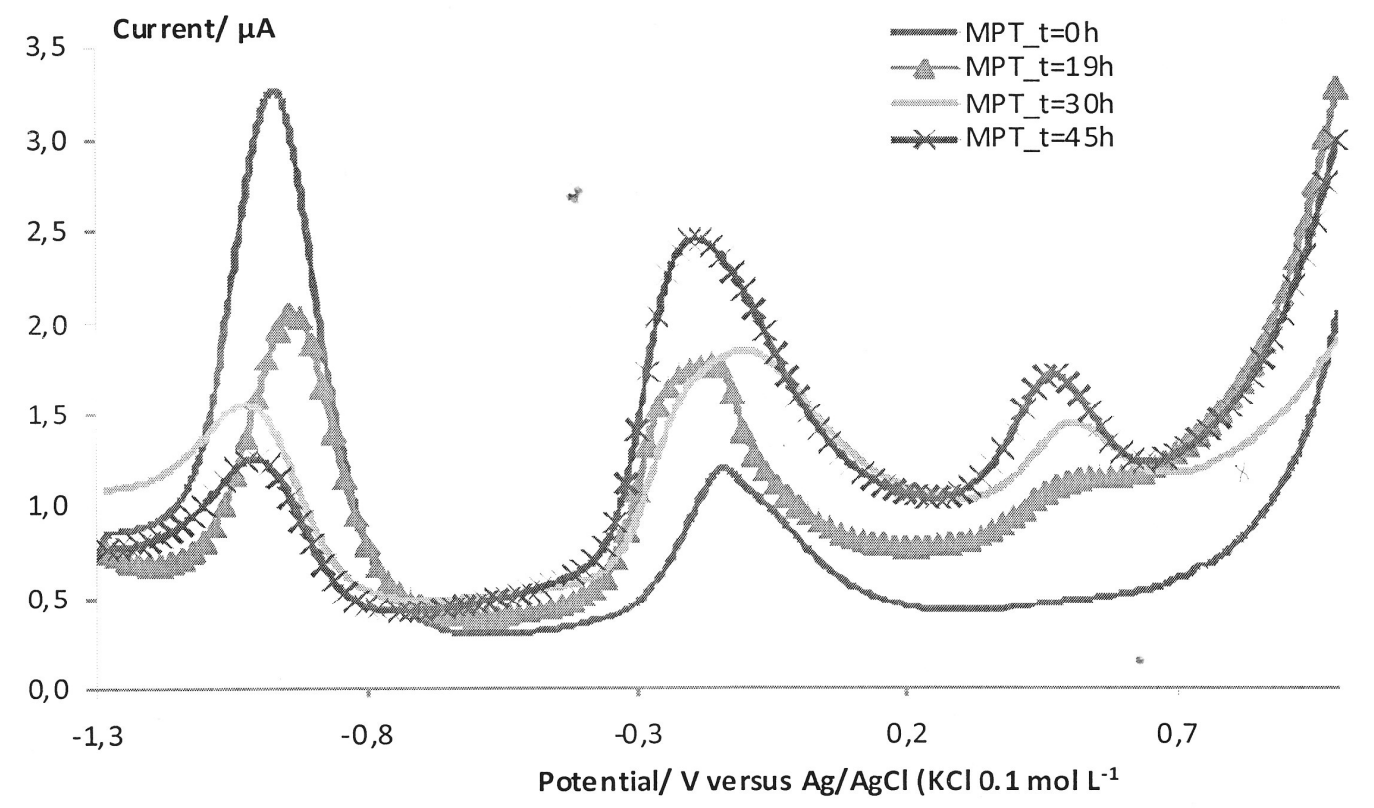

Figure 2: Square wave voltammogramms of MP (200 mg. $\left.\mathrm{L}^{-1}\right)$ in acetate buffer (pH 5.2) following different times. Reference: $\mathrm{Ag} / \mathrm{AgCl}\left(\mathrm{KCl} 0.1 \mathrm{~mol} \mathrm{~L}^{-1}\right)$. 
Table 1: Oxidation and reduction potentials of nitro, hydroxylamine and nitroso groups of MPT and PNP.

\begin{tabular}{lcccccc}
\hline Compound & \multicolumn{2}{c}{ MPT } & \multicolumn{3}{c}{ PNP } \\
\hline Functional group & $\mathrm{NO}_{2}$ & $\mathrm{NHOH}$ & $\mathrm{NO}$ & $\mathrm{NO}_{2}$ & $\mathrm{NHOH}$ & $\mathrm{NO}$ \\
Potential vs & -0.95 & -0.35 & 0.1 & -1.25 & -0.25 & 0.13 \\
$\mathrm{Ag} / \mathrm{AgCl}(\mathrm{KCl} 0.1$ & & & 0 & & & \\
$\left.\mathrm{~mol} \mathrm{~L}{ }^{-1}\right)$ & & & & & & \\
\hline
\end{tabular}

The hypothesis stipulates that in acidic condition ( $\mathrm{pH}$ 5), MP evolves after cleavage of methoxy group of the phosphonate function followed by hydrolysis reaction to $p$ nitrophenol (PNP).

On other hand, the presence of PNP is confirmed by the increase of the background current at $+0.7 \mathrm{~V}$ versus $\mathrm{Ag} / \mathrm{AgCl}(\mathrm{KCl} 0.1$ mol $\mathrm{L}^{-1}$ ). This increase could be attributed to the beginning of oxidation of the phenol group of PNP as described in the literature (Pontié et al., 2011).

Moreover, a deep examination of Figure 2 shows that the intensity of peak III increases over decomposition time from 19 to 45 hours. Comparing the appearance potential of peak III and the signal obtained above for PAP by cyclic voltammetry investigation, one can confirm that this oxidation peak corresponds probably to the oxidation of amino group of PAP generated after MP degradation.

Indeed, through the degradation process of MP illustrated in the Schema 3, the nitro group of MP is reduced to aminoparaoxon methyl by the presence of sulfur derivatives formed probability after desulfuration of $\mathrm{P}=\mathrm{S}$ group to $\mathrm{P}=\mathrm{O}$ and accentuated by the presence of dissolved oxygen. Moreover, the PAP formation during MP decomposition can be also due to acidic condition $(\mathrm{pH}<6)$, which is able to lead to the reduction of nitro group of PNP formed in the media. The reduction of nitro group of PNP is followed by its oxidation yielding others products like quinine and azo-derivatives which isomerize to PAP as a stable byproduct. This result is in agreement with work reported by Manzanilla-Cano et al. (1999).
In summary, one can confirm through this study that MP follows decomposition process in acidic media by generating $p$ nitrophenol (PNP) and $p$-aminophenol (PAP), the stable by-products detectable using CFME. This result constitutes preliminary results and we demonstrated in our mind for the first time that CFME could be used successfully to follow in real time, the degradation of OPs pollutants such as MP.

\section{Conclusion}

We reported an electrochemical monitoring of the degradation of methyl parathion MP using carbon fiber microelectrodes in acetate buffer $\mathrm{pH}$ 5.2. The results we described herein show that CFME could be used to follow MP degradation and to identify selectively its stables metabolites such as PNP and PAP. The obtained results using CFME show that MP is totally decomposed after 45 hours at $\mathrm{pH} 5.2$ in acetate buffer and at laboratory scale. The study, within the framework of environmental monitoring, shows that electrochemical methods can be a cheap alternative for the analysis in situ of some organophosphorus pesticides and their metabolites. In perspective, we will use CFME modified by tetrasulfonated nickel phtalocyanide to analyse and follow the decomposition of MP at low quantity (at residual scale) for in situ use.

\section{ACKNOWLEDGMENTS}

This work was supported by COMSTECH/IFS. Issa Tapsoba thanks International Foundation of Science (IFS) for his grant $n^{\circ}$ W/4394-1. Professor Yvonne 
Bonzi/Coulibaly (Director of the laboratory of Organic Chemistry: Structure and Reactivity LCOSR) was greatly acknowledged for laboratory facilities.

\section{REFERENCES}

Pritchard PH, Cripe CR, Walker WW, Spain JC, Bourquin AW. 1987. Biotic and abiotic degradation rates of methyl parathion in freshwater and estuarine water and sediment samples. Chemosphere, 16: 1509-1520.

Cui X, Hong Li, Lin X. 2002. Electrocatalytic oxidation of hydroxylamine on glassy carbon electrodes modified by hybrid copper-cobalt hexacyanoferrate films. Anal. Sci., 18: 543-547.

De Souza D, Machado SAS. 2006. Study of the Electrochemical Behavior and Sensitive Detection of Pesticides Using Microelectrodes Allied to Square-Wave Voltammetry. J. Electroanal. Chem., 18: 862-872.

Giuliane Castanho M, Carlos MP, Sergio V, Machado AS. 2003. Electroanalytical procedure for the determination of methyl parathion in soil suspensions and its application for sorption studies with Brazilian soils. J. Braz. Chem. Soc., 14: 594-600.

Haouas BK, Tapsoba I, BenKhoud ML, Boujlel K. 2004. Electrooxidation of ortho-substituted aromatic amines. Mechanistic investigation. J. Electroanal. Chem., 571: 241-246.

Jaffrezic-Renault N. 2003. Développements analytiques: micro capteurs électrochimiques pour le suivi in situ des contaminants. Revue F.S.B., 2: 92.

Liu J, Wang L, Zheng L, Wang X, Lee FS. 2006. Analysis of bacteria degradation products of methyl parathion by liquid chromatography/electrospray time-offlight mass spectrometry and gas chromatography/mass spectrometry. $J$. Chromatogr. A., 1137: 180-187.

Manzanilla-Cano JA, Reyes-Salas EO, Barcelo-Quintal 1999. Electrochemical Elimination of the Pesticide Methylparathion in an Aqueous Medium. Int. J. Environ. Anal. Chem., 75: 387-405.

Moctezuma E, Leyva, Palestino G, de Lasa $\mathrm{H}, 2007$. Photocatalytic degradation of methyl parathion: Reaction pathways and intermediate reaction products. $J$. Photochem. Photobiol A. Chem., 186: 7184.

Pontié M, Thouand G, De Nardi F, Tapsoba I, Lherbe S. 2011. Anti-passivating electrochemical process of glassy carbon electrode (GCE) dedicated to nitrophenol compounds oxidation. Electroanalysis, 23: $1579-1584$.

Sbaï M, Essis-Tome H, Gombert U, Breton T, Pontié M. 2007. Electrochemical stripping analysis of methyl-parathion (MPT) using carbon fiber microelectrodes (CFME) modified with combinations of polyNiTSPc and Nafion films. Sensors. Actuators B., 124: 368-375.

Tan X, Li B, Zhan G, Lia C. 2010. Sensitive Voltammetric Determination of Methyl Parathion Using a Carbon Paste Electrode Modified with Mesoporous Zirconia. Electroanalysis, 22: 151-154.

Tapsoba I, Bourhis S, Feng T, Pontie M. 2009. Sensitive and Selective Electrochemical Analysis of Methylparathion (MPT) and 4-Nitrophenol (PNP) by a New Type p-NiTSPc/p-PPD Coated Carbon Fiber Microelectrode (CFME). Electroanalysis, 21: 1167-1176.

Trojanowicz M. 2002. Determination of Pesticides Using Electrochemical Enzymatic Biosensors. Electroanalysis, 14: 1311-1328. 